
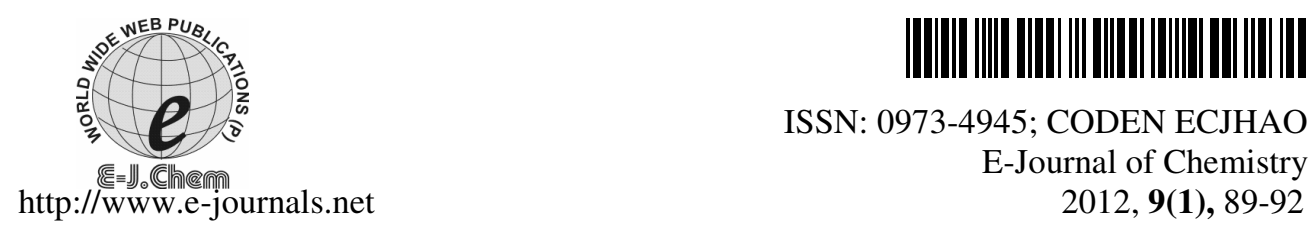

ISSN: 0973-4945; CODEN ECJHAO

E-Journal of Chemistry

2012, 9(1), 89-92

\title{
Spectrophotometric Determination of Zidovudine in Pharmaceutical Dosage Forms
}

\author{
J. SUDHAKAR REDDY ${ }^{\S^{*}}$, MD. S. MAQSOOD AHMED ${ }^{\S}$ \\ I. E. CHAKRAVARTHY and K. PRABHAVATHI ${ }^{\#}$ \\ ${ }^{\S}$ Department of chemistry \\ Osmania College, Kurnool-518001, A.P, India \\ Department of Chemistry \\ Rayalaseema University, Kurnool-518002, A.P, India \\ \#Department of Chemistry \\ S. B. S.Y. M. Degree College, Kurnool-518004, A.P, India \\ jsreddy69@gmail.com
}

Received 13 May 2011; Accepted 31 July 2011

\begin{abstract}
A simple, sensitive and economical spectrophotometric method has been developed for the determination of zidovudine in commercial dosage forms. The method was based on the formation of chloroform extractable complex of zidovudine with wool fast blue. The absorbance of the extractable ion pair complex is measured at the wavelength of maximum absorbance $590 \mathrm{~nm}$ against the reagent blank treated similarly. Statistical analysis proves that the proposed methods are reproducible and selective for the estimation of zidovudine in bulk drug and in its tablet dosage form.
\end{abstract}

Keywords: Spctrophotometry, Zidovudine, Wool fast blue, Formulations

\section{Introduction}

Zidovudine (ZDV), chemically known as 31-azido-31-deoxy thymidine, was the first drug approved for the treatment of AIDS and HIV infection. Zidovudine is a thymidine analogue. It is phosphorylated in the body to zidovudine triphosphate which is the active form that inhibits HIV replication. Zidovudine inhibits the key enzyme reverse transcriptase.

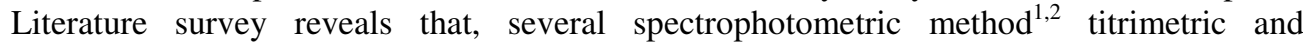
spectrophotometric method ${ }^{3}$, HPLC method $^{4}$ have been reported for the estimation of zidovudine in pharmaceutical formulations. Few analytical methods were reported in literature for the determination of zidovudine and Lamivudine in combinations which includes spectrophotometric method ${ }^{5}$, HPLC $^{6}$ spectrophotometric, first derivative of the ratio-spectra and high-performance liquid chromatography-UV methods ${ }^{7}$. 
Hence, an attempt has been made to develop new UV method for its estimation in pharmaceutical formulations with good accuracy, simplicity, precision and economy.

\section{Experimental}

All absorbance measurements were made on a Spectronic 1001 plus spectrophotometer (Milton Roy Company, USA) with $1 \mathrm{~cm}$ matched quartz cells.

\section{Chemical and reagents}

All the solutions were freshly prepared. All solvents and other chemicals used through this study were of analytical grade. Wool fast blue solution $(0.2 \%)$ was prepared in distilled water. Buffer solutions of required $\mathrm{pH}$ were prepared by mixing appropriate volumes of glycine, sodium chloride and $0.1 \mathrm{M}$ hydrochloric acid. The chemical structure of zidovudine is shown in Figure 1.

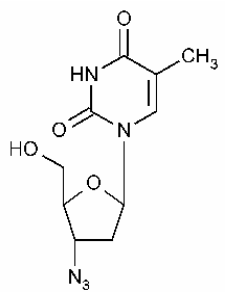

Figure 1. Chemical structure of zidovudine

\section{Preparation of standard solution}

A standard stock solution containing $1 \mathrm{mg} / \mathrm{mL}$ was prepared by dissolving $50 \mathrm{mg}$ of zidovudine in $50 \mathrm{~mL}$ of distilled water. From this, a working standard solution containing $100 \mu \mathrm{g} / \mathrm{mL}$ was prepared for the estimation of proposed method.

\section{Assay procedure}

Aliquots of standard drug solution of zidovudine $0.5-2.5 \mathrm{~mL}$ were taken and transferred into a series of $125 \mathrm{~mL}$ of separating funnels. To each funnel $1.0 \mathrm{~mL}$ buffer solution and $2 \mathrm{~mL}$ of $0.2 \%$ wool fast blue was added. Reaction mixture was shaken gently for 5 min. Then $5 \mathrm{~mL}$ of chloroform was added to each of them. The contents are shaken thoroughly for 5 min and allowed to stand, so as to separate the aqueous and chloroform layer. Colored chloroform layer was separated out and absorbance was measured at $590 \mathrm{~nm}$ against reagent blank. Calibration curve was prepared from absorbance values so obtained (Figure 2).

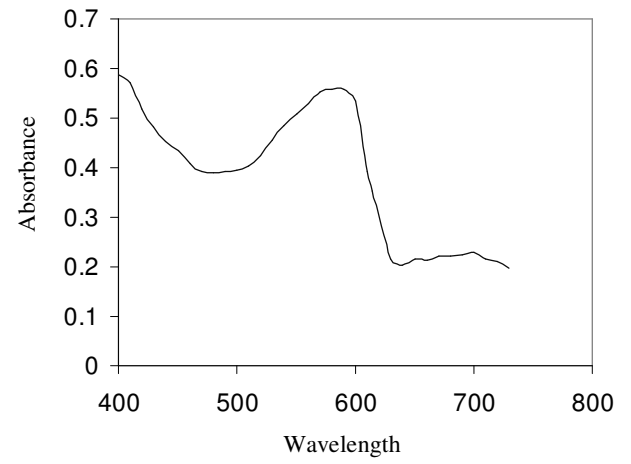

Figure 2. Absorption spectrum of zidovudine with wool fast blue at $590 \mathrm{~nm}$ 


\section{Pharmaceutical preparations}

A total number of twenty tablets of zidovudine accurately weighed and powdered by a mortar and pestle. Tablet powder equivalent to $50 \mathrm{mg}$ of zidovudine was accurately weighed and transferred to $50 \mathrm{~mL}$ volumetric flask. Weighed tablet powder is dissolved in $25 \mathrm{~mL}$ distilled water and shaken for 15 minutes. Then the volume diluted to $50 \mathrm{~mL}$ with distilled water and mix well. The solution was filtered through Whatman filter paper no 42, suitably diluted with distilled water and analyzed as given under the assay procedure for bulk sample. The results are represented in Table 2.

\section{Recovery studies}

To ensure the accuracy and reproducibility of the results obtained, known amounts of pure drug was added to the previously analysed formulated samples and these samples were reanalyzed by the proposed methods and also performed recovery experiments. The percentage recoveries thus obtained were given in Table 2.

\section{Results and Discussion}

The optimum conditions were established by varying one parameter at a time and keeping the others fixed and observing the effect on absorbance of chromogen for the proposed method. In the present work proposed method has been developed for the estimation of zidovudine from tablet formulations. The developed method is based on formation of chloroform extractable colored complexes with wool fast blue. The absorption spectrum of the ion pair complex is shown in Figure 3. The calibration graph of the absorbance versus concentration was found to be linear over the range of $50-250 \mu \mathrm{g} / \mathrm{mL}$ for proposed method. Recovery studies were close to $100 \%$ that indicates indicating good accuracy of the methods. The optical characteristics such as absorption maxima, Beer's law limits, molar absorptivity and Sandell's sensitivity are presented in Table 1 . The regression analysis using method of least squares was made for the slope (b), intercept (a) and correlation (r) obtained from different concentrations and results are summarized. The high molar absorptivities of the resulting colored complexes indicate the high sensitivity of the methods. The percent relative standard deviation, standard deviation and student's ' $t$ ' test values calculated from the five measurements of zidovudine are presented in Table 2. Relative standard deviation values and standard deviation were low that indicates the reproducibility of the proposed methods. In the student's ' $t$ ' tests, no significant differences were found between the calculated and theoretical values of both the proposed methods at 95\% confidence level. This indicated similar precision and accuracy in the analysis of zidovudine in its tablets. The additives and excipients usually present in pharmaceutical preparations did not interfere.

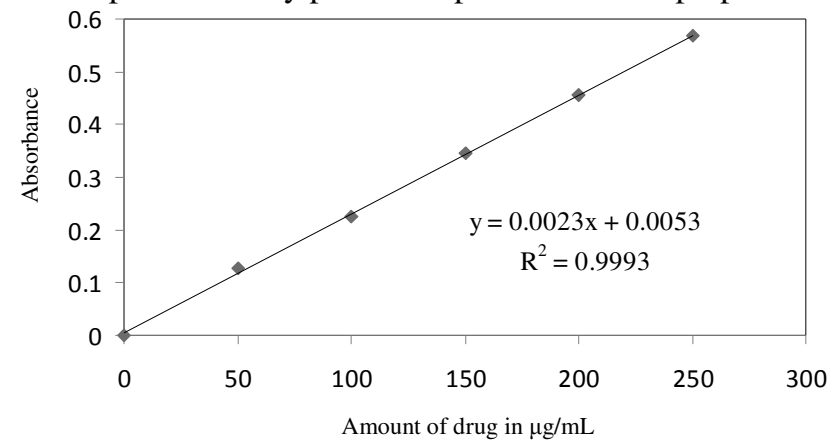

Figure 3. Calibration curve of zidovudine 
Table 1. Optical characteristics of proposed method

\begin{tabular}{|c|c|}
\hline Parameters & Proposed method \\
\hline$\lambda_{\max }, \mathrm{nm}$ & 590 \\
\hline Beer's law limit, $\mu \mathrm{g} / \mathrm{mL}$ & $50-250$ \\
\hline Molar absorptivity, $1 \mathrm{~mole}^{-1} \mathrm{~cm}^{-1}$ & $4.3 \times 10^{3}$ \\
\hline Sandell's sensitivity & 0.4347 \\
\hline Regression equation $(\mathrm{Y}=\mathrm{a}+\mathrm{bC})$ & $Y=0.023 x+0.053$ \\
\hline Slope (b) & 0.023 \\
\hline Intercept (a) & 0.053 \\
\hline Correlation coefficient (r) & 0.9993 \\
\hline
\end{tabular}

Table 2. Assay and recovery of zidovudine in tablet formulations

\begin{tabular}{cccccc}
\hline Tablets & $\begin{array}{c}\text { Labeled } \\
\text { amount, } \mathrm{mg}\end{array}$ & $\begin{array}{c}\text { *Amount found, } \\
\mathrm{mg} \pm \text { S.D }\end{array}$ & $\begin{array}{c}\% \\
\text { Recovery }\end{array}$ & $\% \mathrm{RSD}^{*}$ & ${ }^{*}$ t value \\
\hline ZILION & 300 & $300.13 \pm 0.43$ & 100.24 & 0.1450 & 0.6676 \\
ZIDOVIR & 300 & $300.2 \pm 0.56$ & 100.06 & 0.1891 & 0.7877 \\
ZIDO-H & 300 & $299.96 \pm 025$ & 99.97 & 0.0839 & 0.3555 \\
\hline
\end{tabular}

*Average of five determinations based on label claim

\section{Conclusion}

The proposed method is simple, rapid, accurate and economical and it can be suitable for the determination of the drug either in bulk or in tablets without interference from commonly used excipients and could be used in a quality control laboratory.

\section{References}

1. Basavaiah K and Anil Kumar U R, E-J Chem., 2007, 4(2), 173-179.

2. Basavaiah K and Anil Kumar U R, E-J Chem., 2006, 3(3), 173-181.

3. Basavaiah K and Anil Kumar U R, Indian J Cheml Technol., 2007, 14, 200-203.

4. Ashenafi Dunge, Nishi Sharda, Baljinder singh and Saranjit singh, J Pharm Biomed Anal., 2005, 37, 1109.

5. $\quad$ Erk N, Pharmazie., 2004, 59, 106.

6. Geetha Ramachandran, A K, Hemanthkumar V, Kumaraswami and Soumya Swaminathan, J Chromatogr B., 2006, 843(2), 339-344.

7. Bengi Uslu and Sibel Ozkan A, Anal Chim Acta, 2002, 466(1), 175-185. 


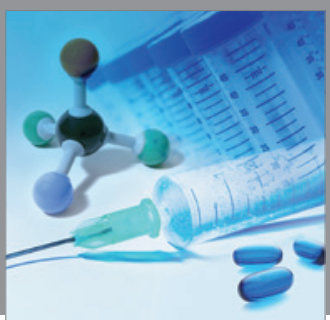

International Journal of

Medicinal Chemistry

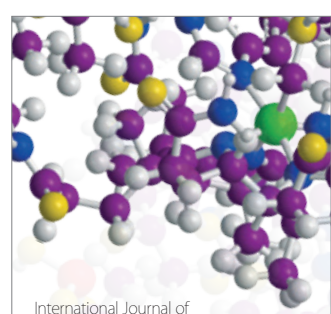

Carbohydrate Chemistry

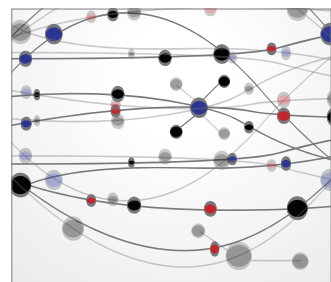

The Scientific World Journal
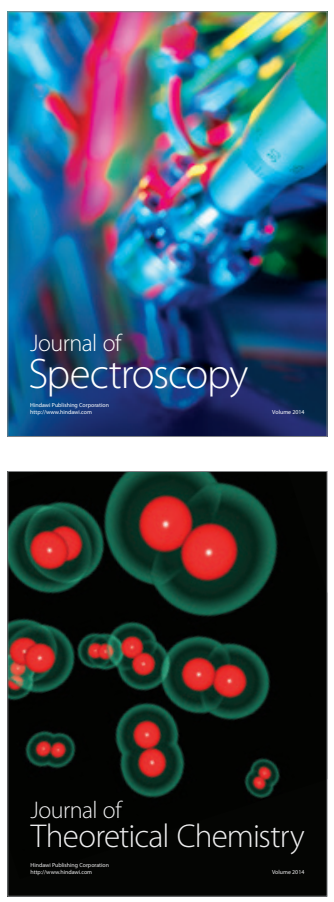
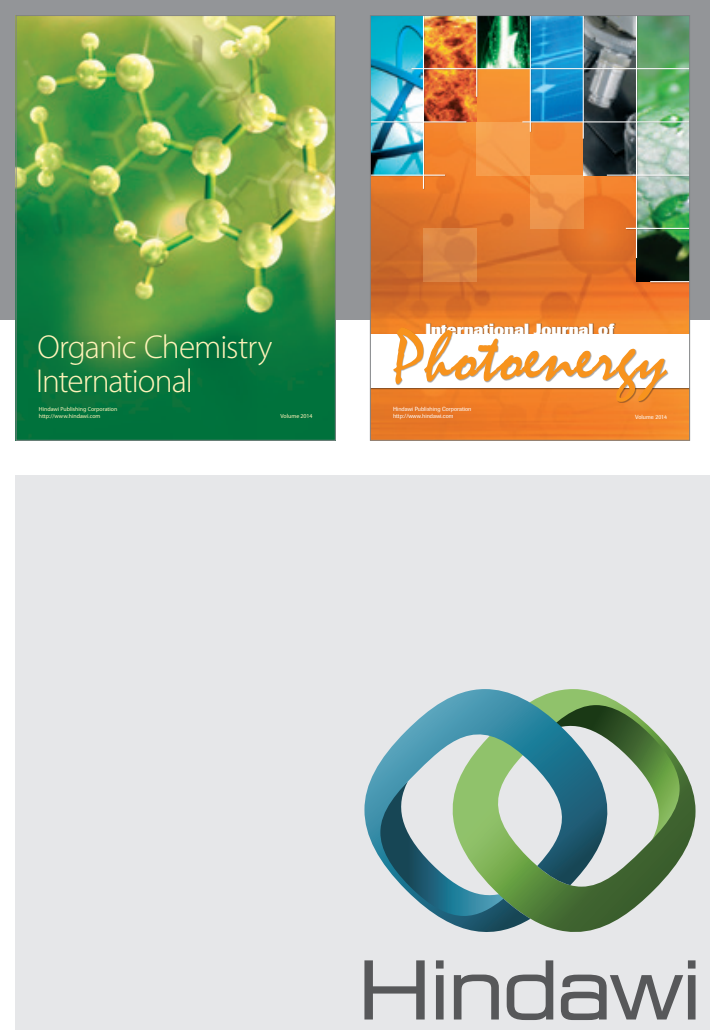

Submit your manuscripts at

http://www.hindawi.com
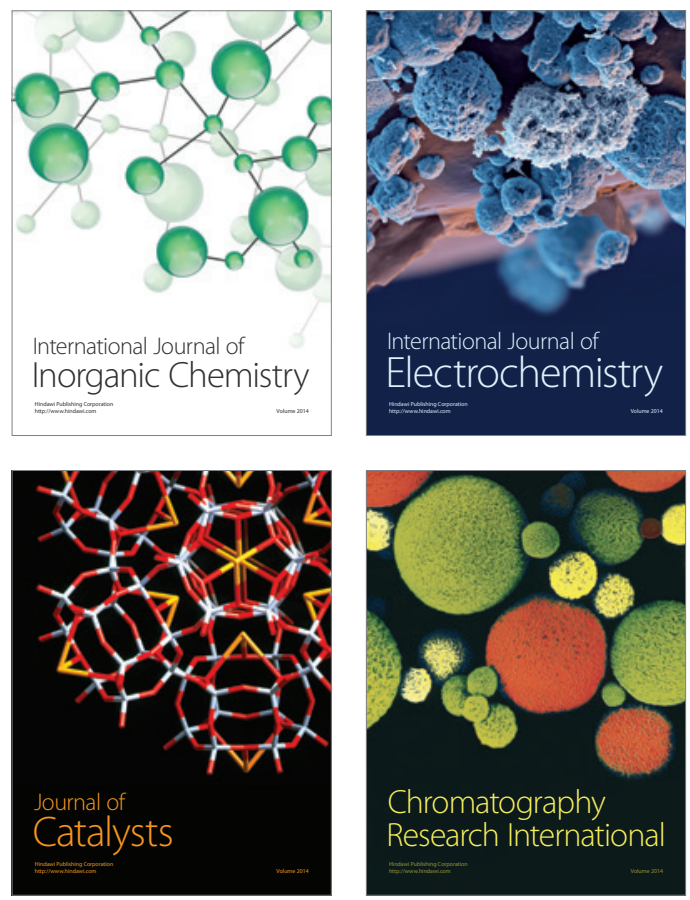
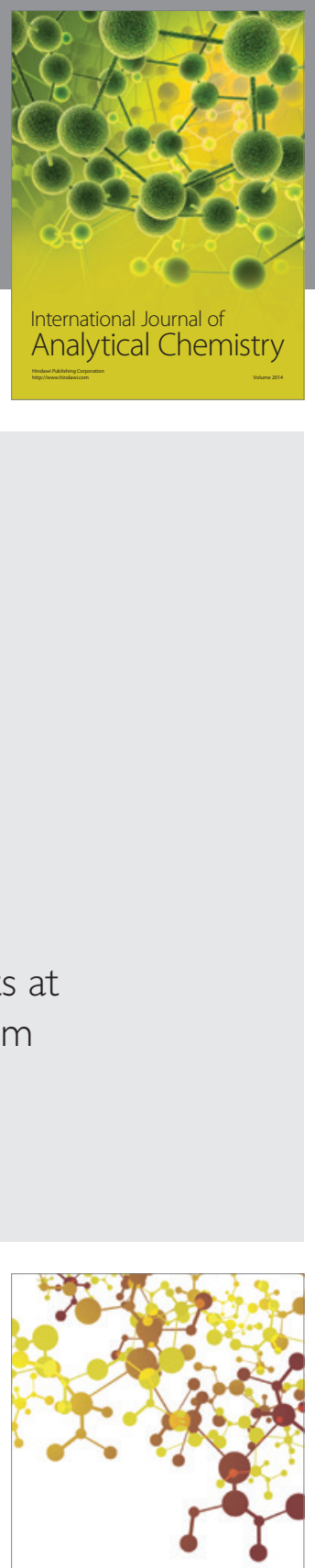

Journal of

Applied Chemistry
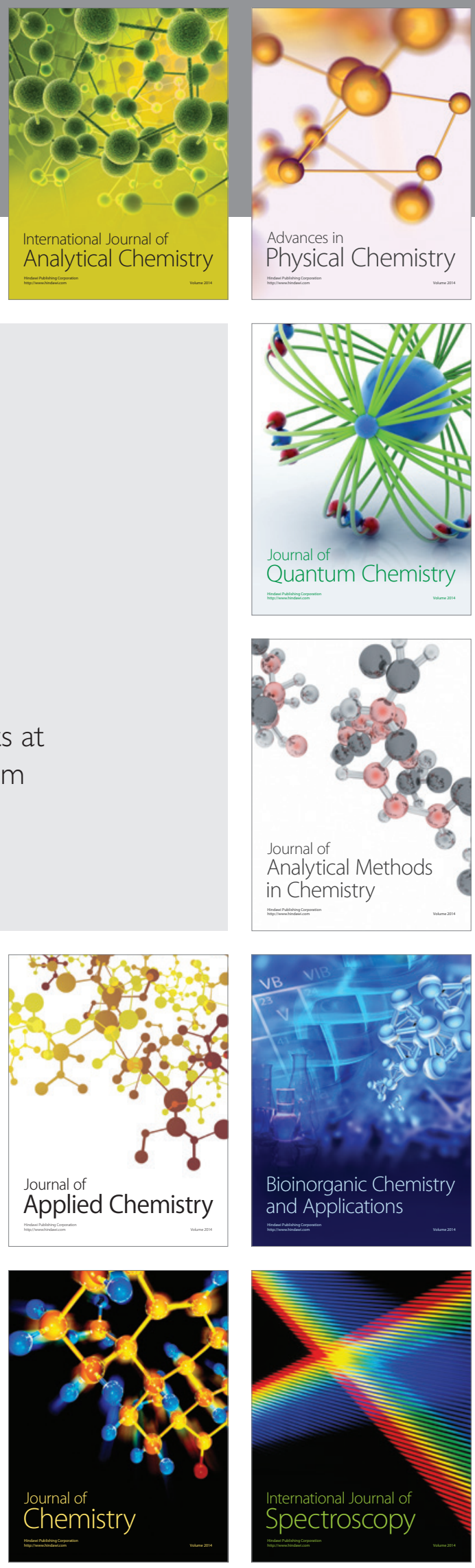